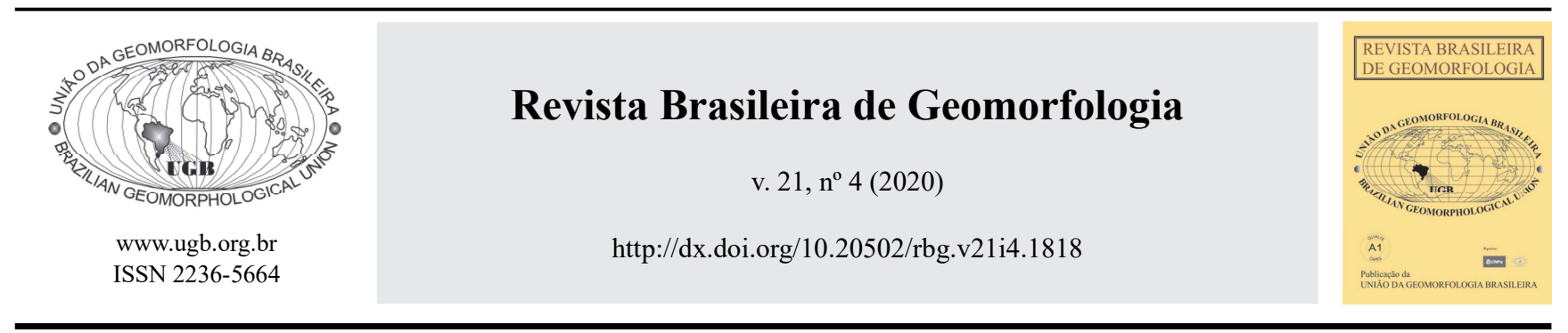

\title{
USO DE VANT E GEOPROCESSAMENTO PARA CÁLCULO DE SOLO ERODIDO EM VOÇOROCA LOCALIZADA NO DISTRITO DE AMADEU AMARAL. MARÍLIA/SP - BRASIL
}

\author{
USE OF UAV AND GIS FOR ERODED SOIL CALCULATION ON \\ A GULLY LOCATED IN THE AMADEU AMARAL DISTRICT, \\ IN MARÍLIA, SP - BRAZIL
}

Carolina Julian

Departamento de Geografia, Universidade Estadual Paulista Júlio de Mesquita Filho Rua Roberto Simonsen, 305, Presidente Prudente, São Paulo. CEP 19060-900. Brasil ORCID: http://orcid.org/0000-0001-9257-3989

E-mail: carolina.julian@unesp.br

João Osvaldo Rodrigues Nunes

Departamento de Geografia, Universidade Estadual Paulista Júlio de Mesquita Filho Rua Roberto Simonsen, 305, Presidente Prudente, São Paulo. CEP 19060-900. Brasil

ORCID: http://orcid.org/0000-0003-3924-4056

E-mail:joao.o.nunes@unesp.br

\begin{tabular}{l}
\hline Informações sobre o Artigo \\
\hline Recebido (Received): \\
05/12/2019 \\
Aceito (Accepted): \\
20/06/2020 \\
\hline
\end{tabular}

Palavras-chave:

Volume de voçoroca; Geoprocessamento; Erosão do solo.

\section{Keywords:}

Gully volume; GIS; Soil erosion.

\section{Resumo:}

O solo é um recurso natural fundamental para a produção de alimentos, que é afetada diretamente devido a sua degradação, sendo que a erosão é uma das principais causas associadas, com quantificação ainda é estudada, devido à complexidade dos processos erosivos. Ferramentas de geoprocessamento são utilizadas como uma forma de análise, nas quais o Veículo Aéreo Não Tripulado (VANT) tem se destacado por sua alta eficiência e custo relativamente baixo. Considerando isso, esse artigo buscou estimar o solo erodido em voçoroca localizada no distrito de Amadeu Amaral, Marília/SP - Brasil. Para isso, foi calculado o volume da erosão utilizando dados do aerolevantamento com VANT e ferramentas de geoprocessamento do software QGis. Estimou-se que foram perdidos cerca de $19.664,61 \mathrm{~m}^{3}$ de solo, aproximadamente $34.806,35 \mathrm{t}$, pelo voçorocamento, resultado esse que, apesar de erros inerentes à metodologia empregada, apresenta uma ordem de grandeza para a quantidade de solo erodido. Assim, além dessa estimativa, a metodologia mostrou possibilidade de ser utilizada para monitoramento da área, que possibilitaria uma melhor compreensão desses processos e obtenção de modelos de predição dessas erosões.

\footnotetext{
Abstract:

Soil is an essential natural resource for food production, which is directly affected for this degradation, whereby erosion is one of the main associated causes, which quantification are still being studied, due to the complexity of the erosion process.
} 
GIS tools are used as a form of analysis, in which the Unmanned Aerial Vehicle (UAV) has stood out for its high efficiency and relatively low cost. Considering this, this article aims to estimate the soil eroded in a gully located in the district of Amadeu Amaral, Marília / SP - Brazil. The erosion volume was calculated using data from the aerial survey with UAV and GIS tools from the QGis software. It was estimated that about $19,664.61 \mathrm{~m}^{3}$ of soil, approximately $34,806.35$ t, were lost due to gullying, a result that, despite errors inherent to the methodology employed, presents an order of magnitude for the amount of eroded soil. Therefore, in addition to this estimate, the methodology showed the possibility of being used to monitor the area, which would enable a better understanding of these processes and obtain prediction models for these erosions.

\section{INTRODUÇÃO}

O solo é um dos recursos naturais de maior importância para a qualidade de vida dos seres humanos, consistindo em elemento fundamental para a produção de alimentos. Sua degradação traz prejuízo socioeconômico, tendo em vista que causa a redução da capacidade de produtividade da terra, considerando tanto a agricultura quanto a pecuária, que caso não controlado, com a utilização de técnicas de conservação, pode acarretar em perdas significativas, causando risco inclusive para as futuras gerações (WADT et al., 2003).

A degradação do solo, geralmente, não é facilmente revertida. Os processos de formação e regeneração dos solos são bastante lentos, tendo em vista que são necessários pelo menos 100 anos para formação ou regeneração de $1 \mathrm{~cm}$ de solo em condições favoráveis, com a adoção de técnicas de manejo adequadas e ocorrência de intemperismo (ARAUJO; ALMEIDA; GUERRA, 2013).

Dentre as principais causas da degradação do solo está a erosão hídrica, subdividida entre laminar e linear. Erosão laminar ocorre quando o fluxo de água na superfície é difuso e arrasta partículas superficiais do solo como um todo. Erosão linear é o processo de remoção do solo com maior intensidade em caminhos específicos, de acordo com a pluviosidade e a superfície do terreno, gerando fluxo concentrado de água, que possibilita o aumentar as dimensões desses caminhos (ARAUJO; ALMEIDA; GUERRA, 2013).

Quando os processos erosivos ocorrem em taxas maiores do que as naturais trazem consequências, tanto para o solo e corpos d'água, quanto para os sistemas de produção agropecuária, reduzindo a fertilidade do solo e a produtividade (GUERRA e JORGE, 2013; WANG et al., 2016).

Dentre as principais e mais complexas formas de erosão estão as voçorocas. Estas são ocasionadas pelo escoamento superficial concentrado até chegar ao nível do aquífero freático suspenso. Além dos fatores naturais associados à evolução desse tipo de processo erosivo, as atividades humanas estão diretamente vinculadas, principalmente quanto as diversas formas de uso e ocupação da terra (IONITA et al., 2015; VERDONK, 2015).

A quantificação de processos erosivos lineares foi iniciada por meio da análise científica em erosões e chuvas simuladas, de forma a compreender o fenômeno e possibilitar sua aplicação em superfícies naturais (KAISER et al., 2014). Conforme Guerra (2002), a forma mais convencional de monitoramento dos processos erosivos, leva em conta a evolução espacial e temporal da voçoroca, especialmente por meio de estacas instaladas próximas as bordas, e as distâncias em relação essa borda. Apesar de todos os avanços dos estudos de quantificação e modelagem de processos erosivos lineares, especialmente de voçorocas, ainda tem sido difícil compreender a complexidade dos processos que envolvem as dinâmicas geomorfológicas dessas feições (POESEN, 2011).

Um avanço nesse aspecto foi possibilitado pelos modelos digitais de terreno (MDT) em nível de detalhe, que permitem uma comparação mais pontual para o entendimento do fenômeno (VERDONK, 2015). Atualmente, existem diversas ferramentas de imageamento da superfície, sendo que, a escolha depende da necessidade do estudo, como os relacionados à precisão, logística e custos (KAISER et al., 2014).

Para este estudo, foi utilizado um Veículo Aéreo Não Tripulado (VANT), devido a sua disponibilidade na Faculdade de Ciências e Tecnologia (FCT/UNESP) e por possuírem uma alta eficiência e acurácia, a um custo relativamente baixo, quando comparado a outras técnicas com resoluções espaciais similares. A tridimensionalidade é obtida pela sobreposição de imagens tiradas pela mesma câmera, que possibilitam a percepção de profundidade (KAISER et al., 2014; VERDONK, 2015). 
Diversos estudos mostram a utilização dessas ferramentas para o estudo de feições erosivas. Kaiser et al. (2014) realizaram o estudo em erosões em áreas de clima árido no Marrocos. Wang et al. (2016) utilizaram VANT e imagem de satélite, junto com medidas em campo, para estudar erosões lineares em diferentes estágios de evolução e compararam as diferenças devido ao uso dessas imagens que possuem resolução espacial diferentes. Verdonk (2015) em sua dissertação de mestrado, utilizou VANT para estudar erosões na Bacia Hidrográfica do rio Salagou, sul da França, calculando seu volume por meio do software ArcGis. Báčová et al. (2019) criaram e validaram um algoritmo para uso no software ArcGis para cálculo de volume de erosões utilizado o MDT.

Neste aspecto, o objetivo principal deste artigo é apresentar o cálculo de solo erodido de uma voçoroca localizada no distrito de Amadeu Amaral, Município de Marília, São Paulo, Brasil, através do uso de produtos gerado por um VANT e geoprocessamento, com software QGis.

\section{CARACTERIZAÇÃO DA ÁREA DE ESTUDO}

A área onde foi desenvolvido este estudo localiza-se no distrito de Amadeu Amaral, a sudoeste do município de Marília/SP (UTM SIRGAS 2000, Zona 22, 596960,662 m E, 7528939,758 m S), conforme mostra a Figura 1. Essa região historicamente sofreu um intenso processo de desmatamento e substituição de sua vegetação nativa por áreas agrícolas, provocando o agravamento dos problemas de erosão laminares e lineares (BEZERRA, 2008).

A propriedade onde se localiza a área de estudo sofreu, assim como a região, esse processo de ocupação, sendo usada inicialmente para cultivos agrícolas que devido ao desgaste da terra foram sendo substituídos por outros menos exigentes, até o uso atual para pecuária de gado de corte. Na propriedade é realizado o pastoreio rotativo, porém sem outras medidas de manejo adequadas, causando a intensificação dos processos erosivos.

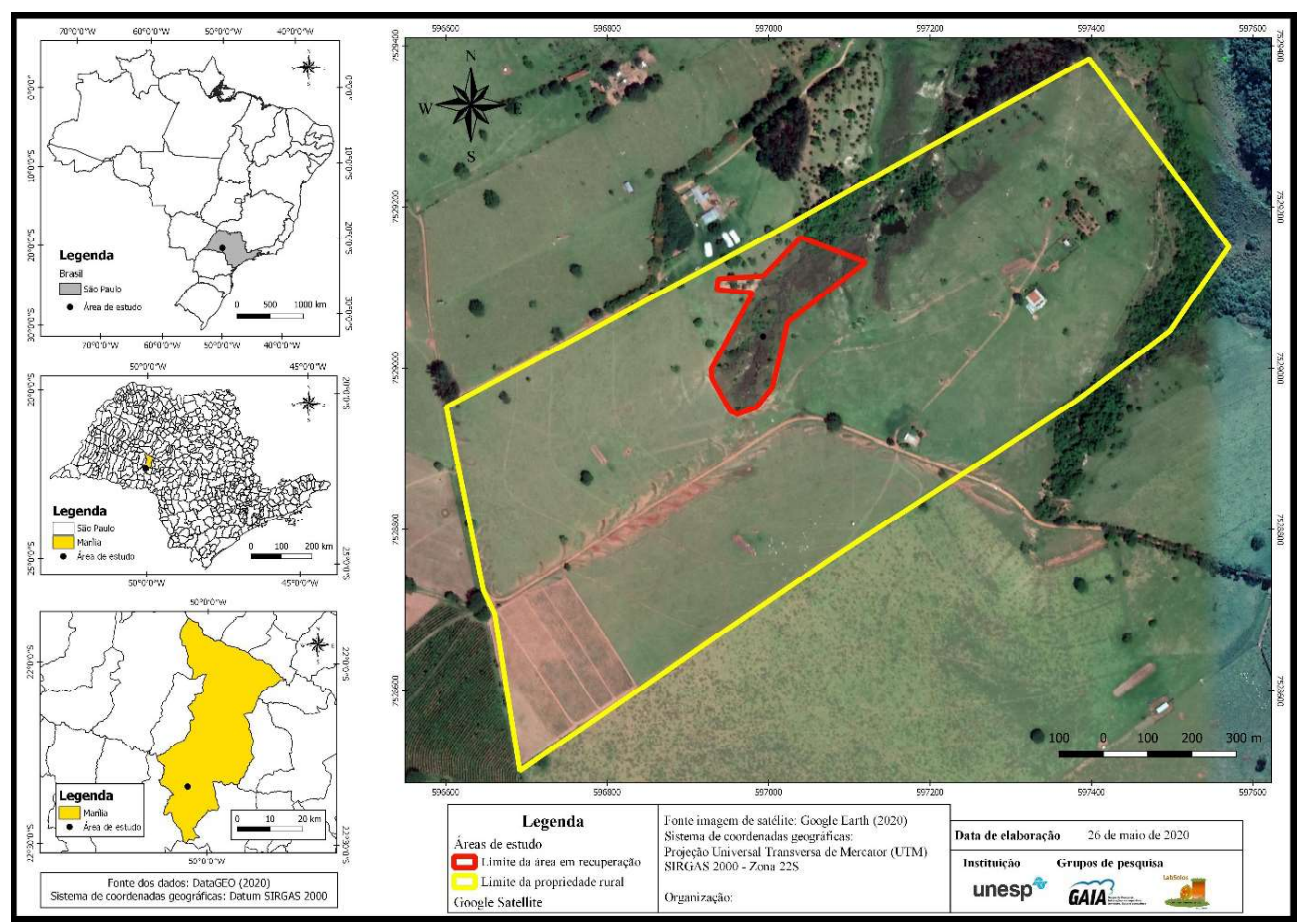

Figura 1 - Localização da área de estudo, com destaque para a área em recuperação (em vermelho) na qual se localiza a voçoroca estudada. Fonte: DATAGEO, 2019; Google Earth, 2019 (adaptado).

No aspecto geomorfológico, a área de estudo está situada no Planalto Residual de Marília. De acordo com o IPT (1981), o relevo do respectivo planalto apresenta predomínio de colinas e morrotes. As colinas em alguns setores são amplas e em outros médias, cujas bordas apresentam escarpas íngremes e festonadas, com fundos de vales amplos. Estruturalmente, o que sustenta o Planalto Residual de Marília são as rochas sedimentares areníticas da Formação Marília (IPT, 1981), constituídos por cimentação carbonática. 
Segundo Ross e Moroz (1997), o Planalto Residual de Marília é uma extensão do Planalto Ocidental Paulista, no qual as formas de relevo predominantes são as colinas com topos aplanados, convexos e tabulares com altimetria variando entre 500 e 600 metros e declividade variando entre 10 a $20 \%$. Ainda conforme Ross e Moroz (1997), a dissecação é média, com densidade de drenagem de média a alta. Neste aspecto, a fragilidade potencial é média, com alta suscetível à processos erosivos, principalmente as áreas de encostas com predomínio de declividade elevada.

Em relação aos arenitos da Formação Marília, estes pertencentes ao Grupo Bauru, sendo que:

[...] a formação Marília depositou-se em um embasamento localizado desenvolvido ao término da deposição Bauru, em situação parcialmente marginal, repousando geralmente sobre a Formação Adamantina e, mais para leste, diretamente sobre os basaltos Serra Geral (IPT, 1981, p. 48).

A Formação Marília caracteriza-se por:

[...] arenitos de granulação fina a grossa, compreendendo bancos maciços com tênues estratificações cruzadas de médio porte. Subordinadamente ocorrem lentes de siltitos, argilitos, e arenitos muito finos. Presença comum de nódulos carbonáticos" (IPT, 1981, p.48).

De acordo com Bezerra (2008), os solos originários da Formação Marília, apresentam os maiores índices erodibilidade, devido as características texturas (franco arenosa), sendo muito friáveis e permeáveis.

Nesse sentido, os solos da região são provenientes da Formação Marília (IPT, 1981), apresentando alta suscetibilidade a erosão. Predominantemente nessa área, foram encontrados solos do tipo Neossolo Quartzarênico, de textura arenosa, com mais de 800 g.kg ${ }^{-1}$ de fração areia, densidade média de $1,77 \mathrm{~g} . \mathrm{cm}^{-3}$, com muitos poros, estrutura grumosa (A) e sem estrutura nos horizontes $\mathrm{C} 1, \mathrm{C} 2 \mathrm{eC}$, não possui plasticidade ou cerosidade e consistência solta ao longo de todo o perfil (NAKATA e JULIAN, 2018).

O clima médio do município de Marília é, segundo Köppen, classificado como Cfa, com precipitação média anual de $1.464,9 \mathrm{~mm}$, sendo mais concentrada no período do verão (DAEE, 2019; JURCA, 2005).

O principal motivo para estudo dessa área é a presença de uma voçoroca. Esta apresenta três ramificações com afloramento do aquífero freático suspenso em todos setores.

\section{MATERIAIS E MÉTODOS}

\section{Levantamento aerofotográfico com VANT}

O voo foi realizado no dia 25 de junho de 2016 , em cooperação com o Laboratório de Astronomia, Topografia e Geodésia (LATOGEO) da FCT/UNESP, Campus de Presidente Prudente/SP - Brasil.

Primeiramente, foi utilizado o software eMotion 2 para elaboração do plano de voo, configurado para uma superposição lateral e longitudinal de $75 \%$ e resolução espacial de $3 \mathrm{~cm} /$ pixel. O voo foi realizado a uma altura média de 70 a 90 metros da superfície.

Em campo, foram implantados alguns pontos de controle, distribuídos uniformemente na área, utilizando receptores GNSS de alta precisão, com método estático rápido, para a geração dos produtos cartográficos e verificação para a análise da qualidade geométrica do produto gerado. O VANT utilizado no levantamento foi o modelo eBee (Figura 2) com câmera RGB Canon elph 110 hs 16.1 megapixels com base no plano de voo realizado (AMORIM, et al., 2016).

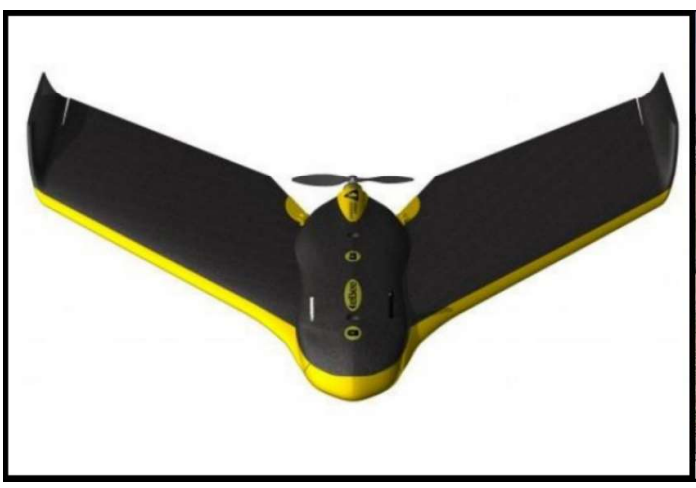

Figura 2 - VANT modelo eBee utilizado para o levantamento. Fonte: SenseFly, 2019. 
As imagens obtidas foram descarregadas no computador e processadas no software Postflight Terra 3D, por meio de aerotriangulação, gerando uma nuvem de pontos, obtendo a ortofoto e Modelo Digital de Superfície (MDS), processada para obter o Modelo Digital do Terreno (MDT).

\section{Cálculo do volume da voçoroca}

As ferramentas utilizadas para o cálculo do volume da erosão foram baseadas nos trabalhos de Verdonk (2015) e Báčová et al. (2019). Em seus estudos, os autores utilizaram MDTs, obtidos por meio de processamentos de aerolevantamentos com VANTs, para interpolar a superfície anterior ao processo erosivo mediante delimitação manual das partes iniciais (bordas) da erosão. Os volumes das voçorocas em ambos os estudos foram obtidos pela subtração dos dois modelos de elevação: superfície original (interpolada) e da erosão atual. Ambos os trabalhos utilizaram ferramentas do software ArcGis, sendo que Báčová et al. (2019) na forma de Python elaborado pelos autores e Verdonk (2015) pelo "Cutfill", no modo 2D, e "EnterVol", no modo 3D do software. Considerando isso, a metodologia geral realizada pelos autores foi adaptada para ferramentas básicas disponíveis em software livre, no caso o QGis 3.4.9.

Assim, foram carregadas no software a altimetria, no formato de MDT e curvas de nível e ortofoto, que auxiliaram na delimitação da voçoroca. A partir desses dados foi delimitado manualmente o contorno das partes iniciais (bordas) da erosão por meio da criação de um shapefile de polígono (Figura 3). Desse polígono foram extraídos os vértices (Figura 3), utilizando a ferramenta "Extrair Nós", posteriormente utilizados para estimar a superfície original.

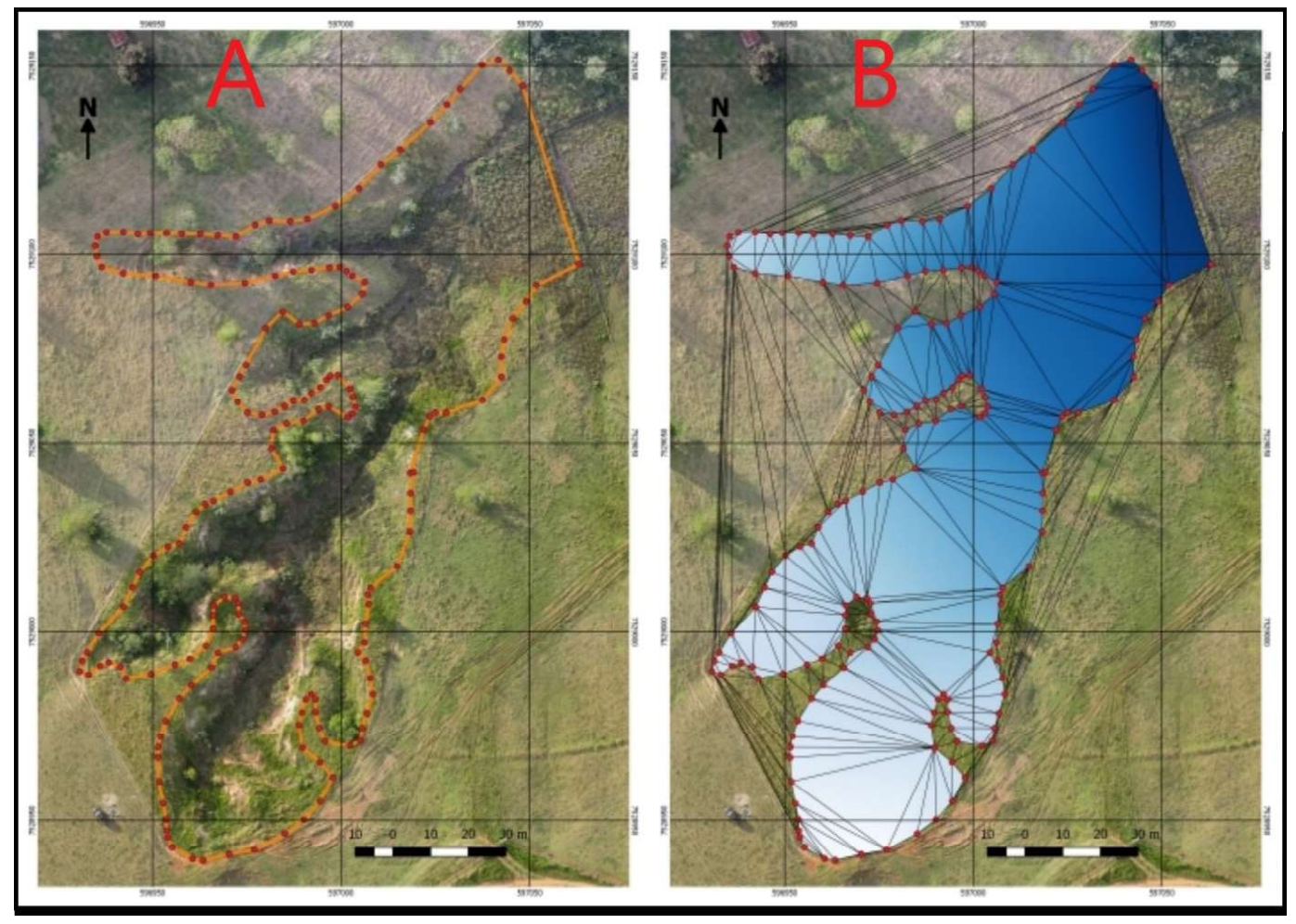

Figura 3 - Delimitação da voçoroca (em A) e malha triangular e superficie original criada(em B) a partir dos vértices (em A). Fonte: autores, 2019.

Para que os vértices obtivessem o atributo de altitude do raster, foi utilizada a ferramenta "Add raster values to points", selecionando como elementos o shapefile com os vértices do contorno e o raster MDT. O shapefile criado possui a localização dos vértices da delimitação da voçoroca na forma de pontos e a altitude nesses locais como atributo.

Em seguida, foi feita a interpolação de uma malha triangular ou TIN (Triangle Irregular Network), por meio da ferramenta "Interpolação TIN", tendo como elementos os vértices com altitudes, sendo atributo da interpolação a camada da altitude (Figura 3). Para este caso, foi utilizado como método de interpolação o Linear e tamanho do pixel $0,16838 \mathrm{~m}$, que é a resolução do MDT original do levantamento. O resultado foi recortado, utilizando a ferramenta "Recortar raster pela camada de máscara", com o TIN interpolado como entrada e o shapefile de polígono da voçoroca como máscara, para obter o TIN somente para área delimitada da voçoroca (Figura 3). 
Para realizar o cálculo da diferença de altitude entre a superfície original interpolada e a obtida com o aerolevantamento com VANT, foi utilizada a ferramenta "Calculadora Raster", disponível na guia Raster do QGis. Foi realizada a subtração do TIN recortado para o MDT com situação atual da erosão (Equação 1), obtendo assim, a diferença de altitude, ou seja, a profundidade, de cada pixel dentro da delimitação da voçoroca.

\section{Profundidade $=$ Superficie original (TIN)-MDT altimetria VANT}

Para cálculo do volume foram multiplicados os valores da profundidade pela resolução do pixel. Para isso, foram extraídos os pontos do raster da profundidade utilizando a ferramenta "gdal2xyz", que converte o arquivo raster para tipo $c s v$, contendo as coordenadas do centro de cada pixel e sua profundidade calculada.

Com esse arquivo, as profundidades calculadas foram multiplicadas pela resolução do raster de origem, obtendo volume de cada pixel. Esses valores foram somados para obter o volume total perdido com a erosão, convertido também para massa de solo, por meio da densidade. Foram analisados também os valores negativos, a fim de verificar o erro associado ao valor obtido.

\section{RESULTADOS}

O estudo sobre a voçoroca iniciou-se com a verificação das condições existentes que podem influenciar direta ou indiretamente, na evolução do quadro erosivo na área. A voçoroca em estudo pode ser classificada quanto ao seu tipo e forma, como ramificada, informação importante ao se analisar os fluxos de escoamento e evolução da erosão.

A partir do perfil morfológico, esquematizado na Figura 4, podem ser observadas as inter-relações do substrato geológico, do tipo de solo e dos fluxos de infiltração. O substrato geológico na área é composto de rochas sedimentares da Formação Marília, que originaram os Neossolos Quartzênicos, presentes a montante da voçoroca, que com os contínuos processos erosivos causaram acúmulo de sedimentos arenosos e inconsolidados no setor a jusantes da mesma. Ressalta-se no esquema que com o surgimento da voçoroca os fluxos de infiltração de água, que formam os aquíferos freáticos suspensos, foram sendo alterados em comparação com a condição original, tendo redução da infiltração até o nível do aquífero e ocorrência em maior intensidade dos escoamentos superficial e subsuperficial.

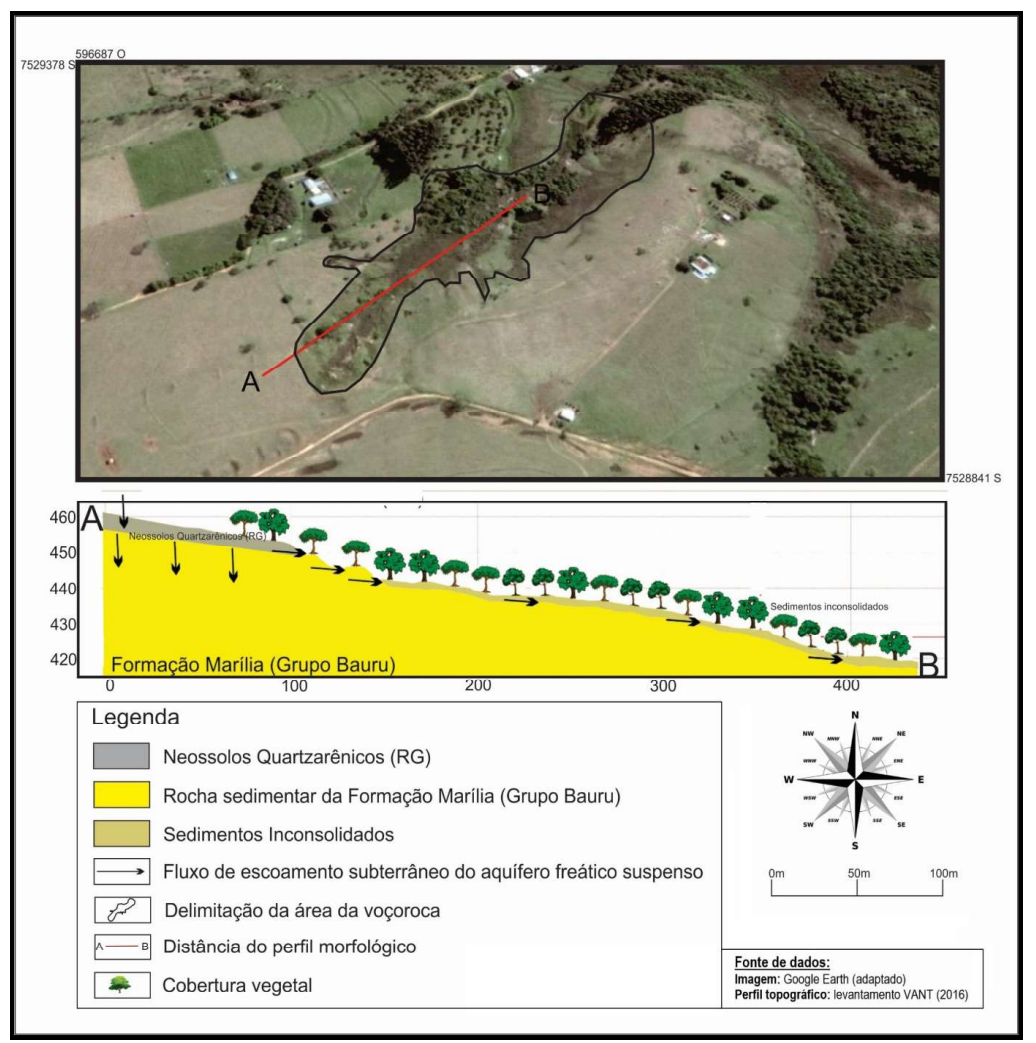

Figura 4 - Perfil morfológico das cabeceiras da voçoroca, localizada no distrito de Amadeu Amaral, município de Marília-SP. Fonte: autores, 2019; Google Earth, 2019 (adaptado). 
A cobertura vegetal predominante da propriedade é de gramíneas, incluindo a área em recuperação sendo que nela há presença de árvores isoladas, tanto no entorno quanto dentro da erosão. Na data de realização do aerolevantamento com VANT, a erosão já havia sido cercada, Figura 5A, portanto a cobertura vegetal da área já estava bem desenvolvida e criando uma estabilidade dinâmica no foco erosivo da área, conforme Figura 5B, tornando a vegetação um fator a ser avaliado.

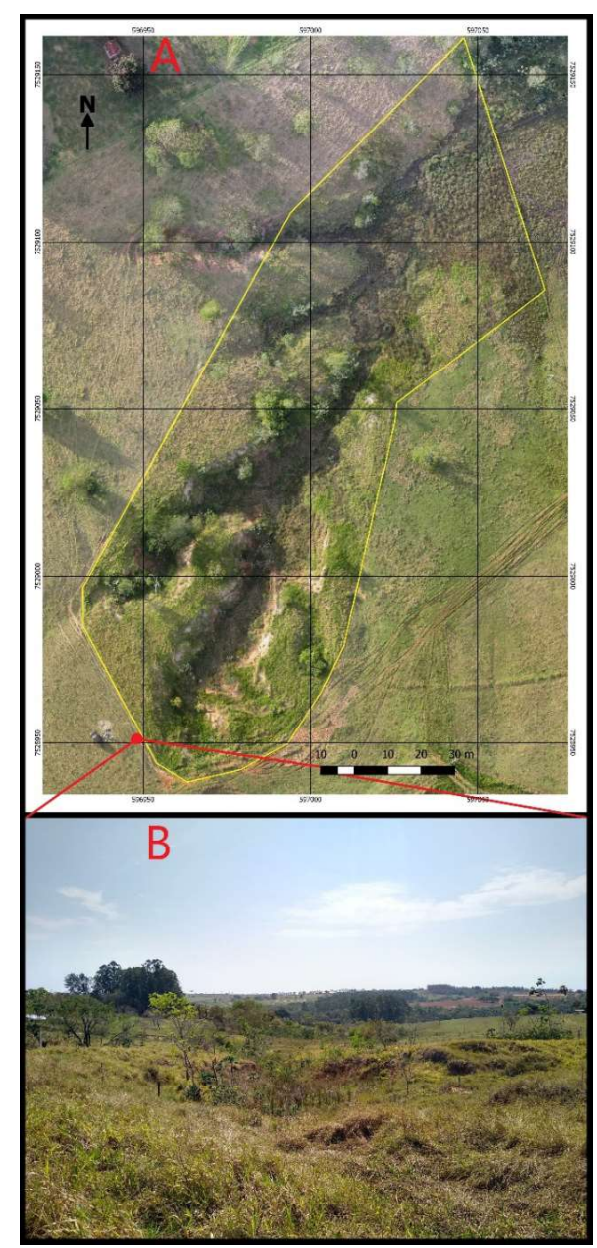

Figura 5 - Ortofoto da voçoroca, em A, com destaque para a área cercada em amarelo, e foto da voçoroca com ângulo de montante para jusante, em B. Fonte: autores, 2019.

Considerando a presença da vegetação de grande porte na área, para o cálculo do volume, foi necessário filtrá-las do levantamento, a fim evitar cálculo equivocado do volume de solo perdido. Na Figura 6A, é apresentado o MDS, onde é possível observar a diferença de altitude, "manchas" claras, devido a presença de árvores dentro da área delimitada. A filtragem da vegetação de grande porte é apresentada na Figura 6B, sendo que esta não apresenta "manchas" claras associadas a vegetação e mostra uma maior homogeneidade em relação ao MDS.
Com a delimitação do limite (bordas) da voçoroca, determinou-se que a mesma possui $10.994 \mathrm{~m}^{2}$ de área $\mathrm{e}$ $868,9 \mathrm{~m}$ de perímetro. Além disso, foi calculado que o comprimento máximo da voçoroca é de cerca de $220,10 \mathrm{~m}$ de comprimento e 49,96 m de largura, próximo à área com maior profundidade, valores esses que variam de acordo com os trechos onde as medidas foram realizadas, sendo que os utilizados foram destacados na Figura 7. Obteve-se como profundidade máxima da erosão em relação a superfície original interpolada, o valor de 6,80 m na região mais clara da Figura 7. 
Julian C. \& Nunes J. O.R.
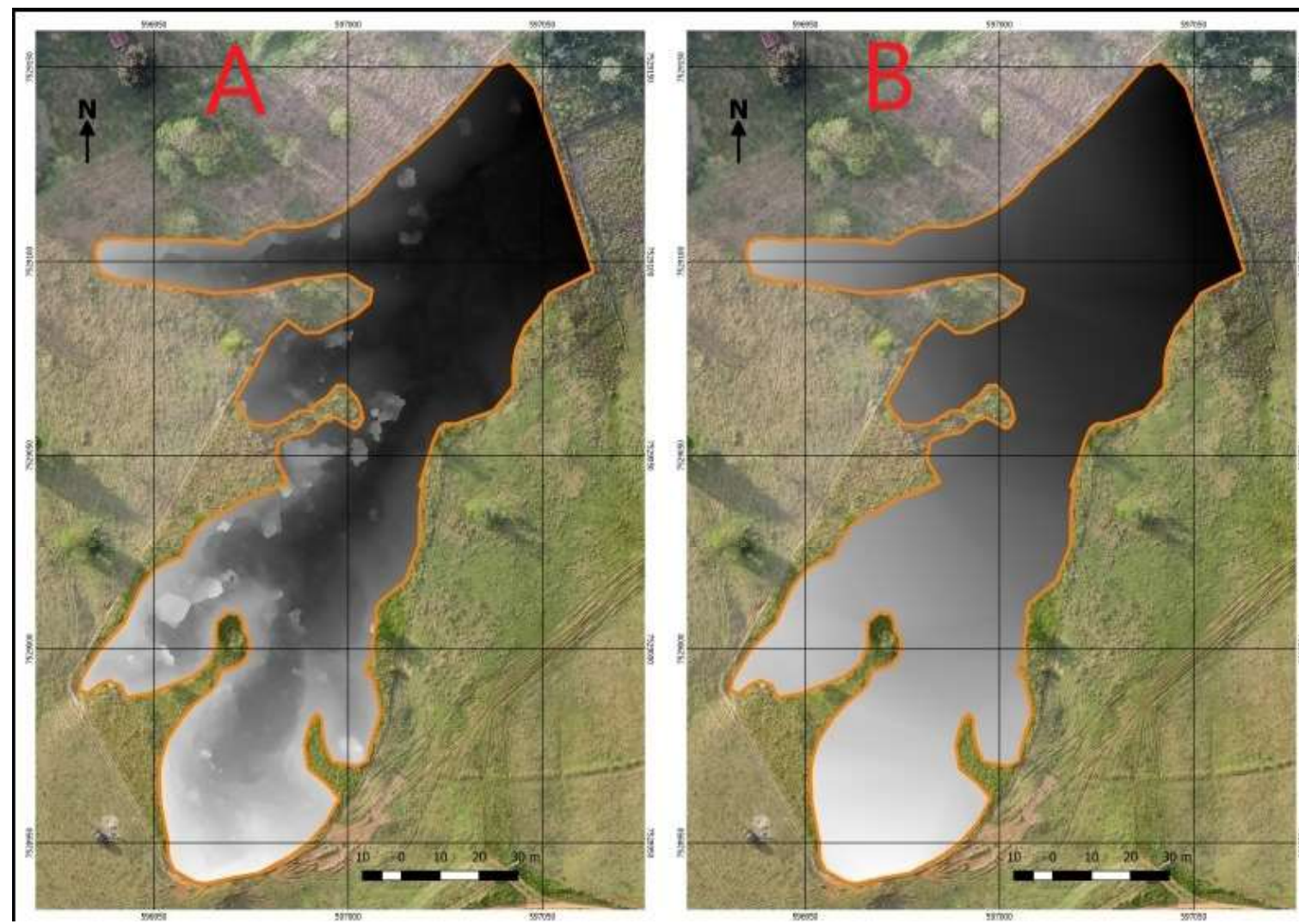

Figura 6 - Modelo Digital de Superficie (MDS), em A, gerada com o levantamento com VANT e Modelo Digital de Terreno (MDT), em B, obtida a partir do MDS. Fonte: autores, 2020.

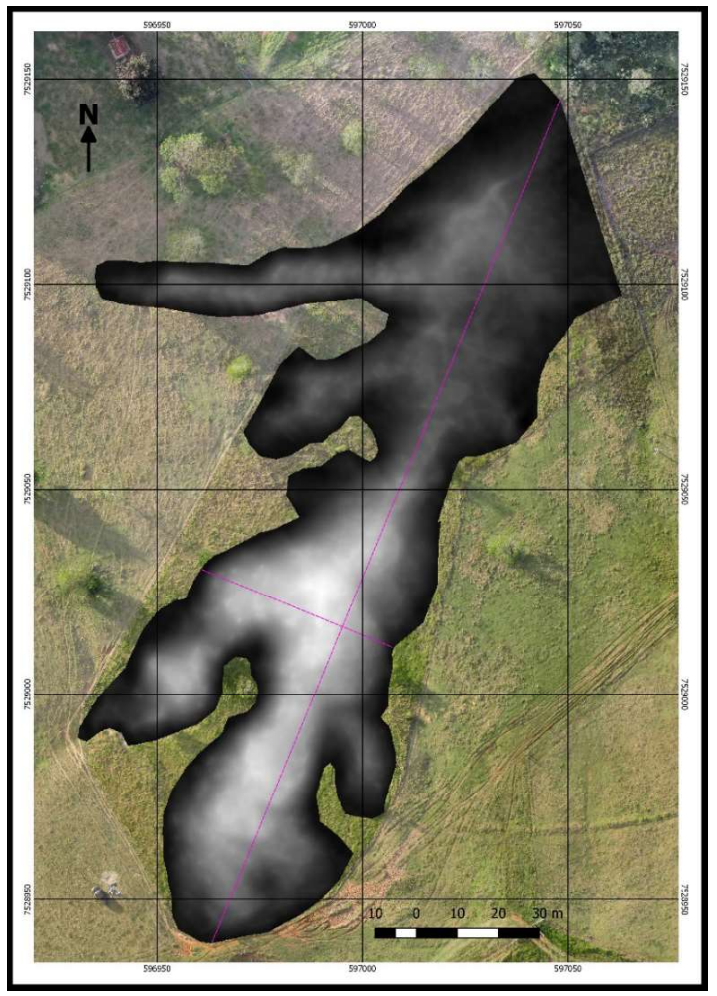

Figura 7 - Imagem da profundidade relativa a superficie original interpolada, com destaque tracejado rosa das medidas de comprimento e largura da erosão. Fonte: autores, 2019. 
O volume estimado de solo erodido na voçoroca foi de $19.664,61 \mathrm{~m}^{3}$, carreado pelo escoamento superficial durante o tempo de sua formação até a data do aerolevantamento da área. Considerando a densidade média do solo, foram erodidas aproximadamente $34.806,35 \mathrm{t}$ de massa de solo.

Analisando os erros da metodologia e considerando o volume total, calculou-se que $0,22 \%$ desse valor é associado a valores negativos (erros) na profundidade. Assim, caso fossem considerados somente os resultados positivos calculados seria obtido um acréscimo de $44,13 \mathrm{~m}^{3}$ no valor total, resultando em 19.708,74 $\mathrm{m}^{3}$ de solo erodido.

Ao observar o erro da metodologia considerando a quantidade de células, essas percentagens são alteradas.
De um total de 388.136 células, 368.312 células (94,9\%) possuem valores positivos, associados ao solo erodido, e 19.823 células $(5,1 \%)$ valores negativos, relacionado a estimativa incorreta da superfície original. Esses valores negativos, destacados em vermelho na Figura 8, localizam-se próximos ao limite estimado para a voçoroca, onde há uma transição entre o topo e os taludes.

Essa variação pode estar associada à definição do limite da erosão e/ou forma do relevo nesses locais. As vertentes próximas aos pontos onde foram identificados os erros nos cálculos possuem forma convexadas, conforme a Figura 9, que podem ser um dos fatores de dificuldade na delimitação do limite da erosão e interpolação da superfície original.

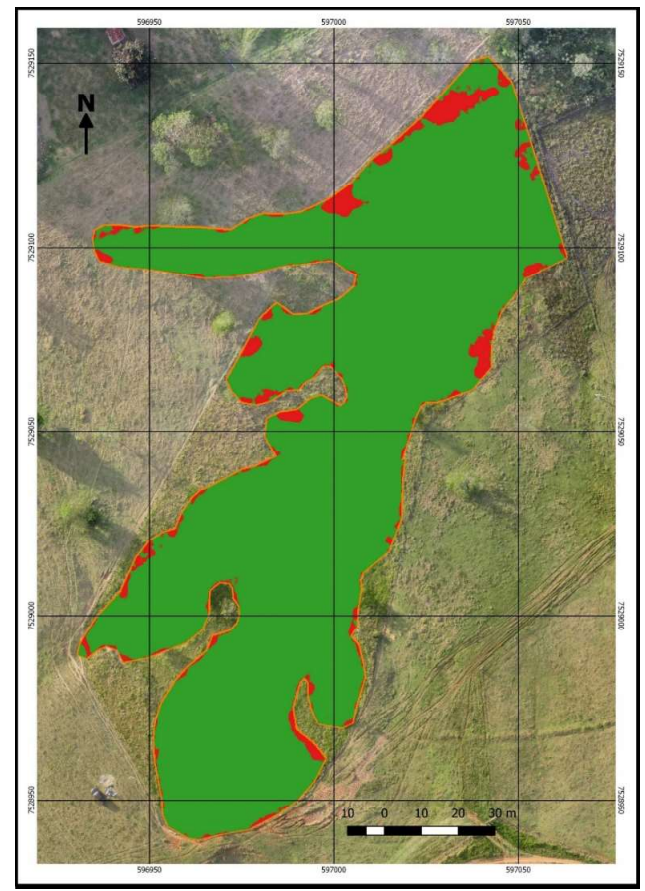

Figura 8 - Imagem colorida ilustrando a localização dos valores positivos (verde) e negativos (vermelho) estimados. Fonte: autores, 2019.

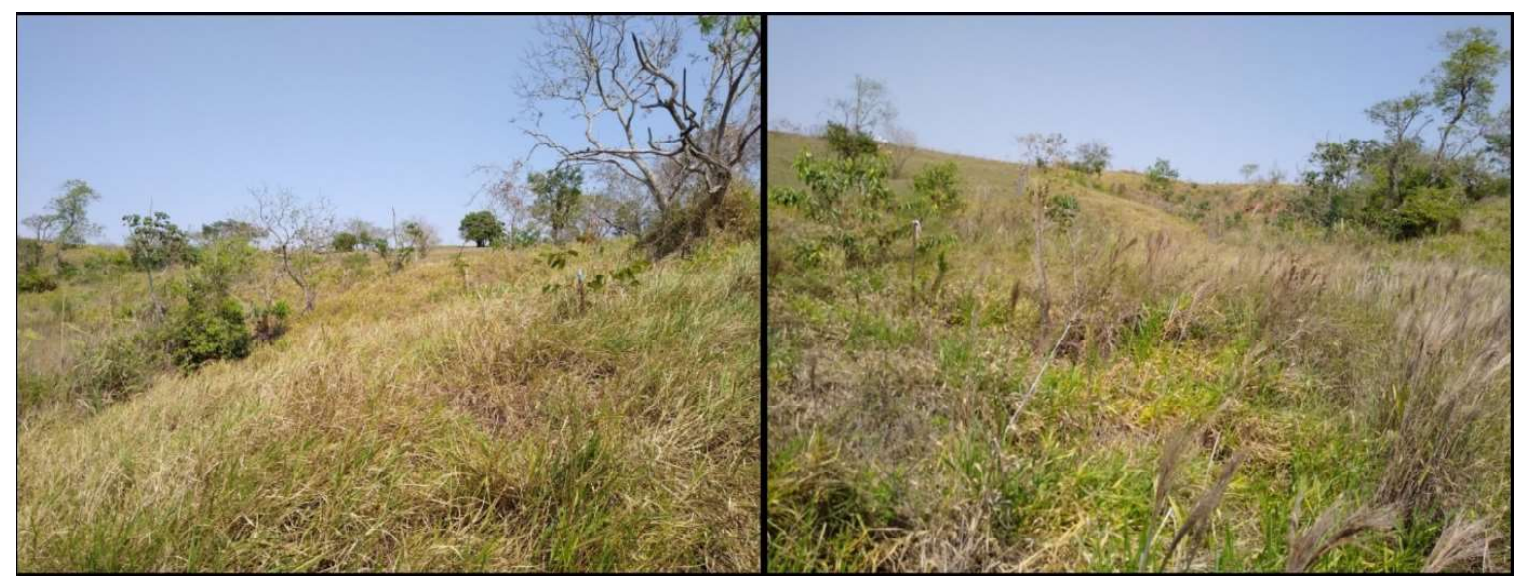

Figura 9 - Fotos em campo ilustrando morfologia encontrada nos locais onde houveram erros de cálculo.Fonte: autores, 2019. 
A definição dos limites da erosão influencia diretamente na interpolação da superfície original e esse é um processo manual. Além disso, esse processo de interpolação da superfície é limitado, e cria uma superfície mais aplainada, podendo ocasionar em cortes no relevo devido a sua irregularidade natural. Apesar disso, a percentagem de erro no cálculo do volume da erosão é menor que a quantidade de células com valores errôneos (negativos), mostrando que o valor possui ordem de grandeza demonstrativa da realidade.

\section{DISCUSSÕES}

Os valores calculados para o caso estudado, mostram uma estimativa da quantidade de solo perdido no processo de formação e evolução da voçoroca significativos para mensuração de sua ordem de grandeza.

A maior dificuldade na metodologia utilizada é na definição do limite da erosão, e consequentemente na interpolação da superfície original do terreno. Isso gera os principais erros nas estimativas desse trabalho, relacionados à interpolação da superfície anterior à erosão, fator também verificado por Báčová et al. (2019). Uma perspectiva futura para melhoria da metodologia seria a criação de uma ferramenta de delimitação automática que possibilitasse uma menor ambiguidade.

Por não existir imagem da área anterior a existência da voçoroca não é possível calcular com maior exatidão o volume de solo erodido nem a taxa de erosão. Considerando que, normalmente, assim como nesse caso estudado, não se tem informações sobre a superfície original das erosões, como apontado por Báčová et al. (2019), esses erros tornam-se aceitáveis e passíveis de consideração quando se analisa erosões desse tipo e sua continuidade, como uma forma de monitoramento, torna possível uma compreensão maior dos processos envolvidos na sua evolução.

Um fator de destaque é a necessidade de utilização de imagens com alta resolução, como a de um VANT, devido a resolução espacial oferecida imagens de satélite de disponibilidade gratuita e atualizada não serem compatíveis com esse tipo de estudo. Esse é um fator agravante para realidade brasileira, devido à dificuldade de obtenção de imagens com alta resolução para análises de feições erosivas, devido ao alto custo para aquisição de imagens de satélite com resolução espacial adequada ou custo para realização de aerolevantamentos por empresas particulares, quando não disponíveis nas universidades para pesquisa.

Ainda que a metodologia apresente essas dificuldades, ela se destaca pela rapidez na qual pode ser obtida e pela possibilidade do monitoramento da erosão pela comparação de imagens ao longo do tempo, como para verificação do aumento de suas dimensões, inclusive de sua profundidade, pela diferença de altitudes entre imagens em datas diferentes, que além disso possibilita a estimativa da perda de solo entre esses dois períodos e em relação a superfície original já interpolada.

Ademais, o uso do VANT para monitoramento de voçorocas pode ser associado a técnicas convencionais, por meio da identificação das localizações das estacas de monitoramento na imagem, podendo ser utilizadas para comparar com as distâncias medidas em campo.

Por ainda não existir modelos confiáveis e válidos que permitam prever os efeitos de uma voçoroca em escala espacial e temporal, essa metodologia de cálculo apresenta uma perspectiva de auxílio na compreensão dos processos erosivos lineares e obtenção de modelos para predição das mesmas.

\section{CONCLUSÕES}

O cálculo do solo erodido em uma voçoroca utilizando dados gerados por meio de levantamento com VANT e ferramentas de geoprocessamento se mostrou simples e adequada para a intencionalidade do traba1ho. A metodologia permitiu cálculo de uma ordem de grandeza para a quantidade de solo erodido na voçoroca durante seu processo de formação e evolução.

As maiores alterações dos valores calculados ocorrem devido a não existência de uma imagem anterior a erosão e a necessidade de sua interpolação por meio de processos manuais pelo usuário. Para estudos futuros de melhoria da metodologia utilizada pode ser feita a formulação de ferramenta de delimitação automática e estudos de voçorocas que possuem imagens anteriores a sua existência para ajuste e/ou correção dos valores obtidos.

A metodologia apresenta potencial para estudo e monitoramento de erosões lineares, porém para isso é necessária a disponibilização de ferramentas adequadas para isso, como levantamentos em nível de detalhe com informações necessárias para maior aprofundamento nos estudos realizados. 


\section{REFERÊNCIAS BIBLIOGRÁFICAS}

AMORIM, A.; PESSOA, G. G.; LEMES, I. R.; KOMAZAKI, J. M.; JORGE, L. C.; GALO, M.; CAMARGO, P. de O. Utilização de VANT para o georreferenciamento de imóveis rurais. In: SEMINÁRIO INTERNACIONAL UAV, 1, 2016, Lisboa. Anais... Lisboa: Actas, 2016. p. 25 - 36

ARAUJO, G. H. de S.; ALMEIDA, J. R. de; GUERRA, A. T. Gestão ambiental de áreas degradadas. ed. 9. Rio de Janeiro: Bertrand Brasil, 2013.

BÁC̆OVÁ, M.; KRÁSA, J.; DEVÁTÝ, J.; KAVKA P. A GIS method for volumetric assessments of erosion rills from digital surface models. European Journal of Remote Sensing, vol 52, S1, p. 96-107, 2019. DOI: 10.1080/22797254.2018.1543556.

BEZERRA, M.A. Influência do uso da terra na incidência de processos de dinâmica superficial na região de Marília (SP). Guarulhos, 2008. 150 f. Dissertação (Mestrado em Análise Geoambiental) - Centro de Pós-graduação e Pesquisa-CEPPE, Universidade Guarulhos.

DEPARTAMENTO DE ÁGUAS E ENERGIA ELÉTRICA (DAEE). Banco de Dados Hidrológicos: pluviométricos prefixo D6-025. Disponível em <http://www.hidrologia.daee. sp.gov.br/> Acesso em: 29 fev. 2020.

GUERRA, A. J. T.; JORGE, M. do C.O. Processos erosivos e recuperação de áreas degradadas. São Paulo: Oficina de Textos, 2013.

GUERRA, A. J. T. Processos erosivos nas encostas. In: CUNHA, S. B. da.; GUERRA, A. J. T. (Org.). Geomorfologia - Exercícios, técnicas e aplicações. Rio de Janeiro: Bertrand Brasil, 2002. Cap. 4, p. 139-155.

IONITA, I., FULLEN, M. A., ZGŁOBICKI, W., POESEN, J.. Gully erosion as a natural and human-induced hazard. Natural Hazards v. 79, p. S1-S5, 2015. DOI: https://doi.org/10.1007/ s11069-015-1935-z.

INSTITUTO DE PESQUISAS TECNOLÓGICAS DO ESTADO DE SÃO PAULO (IPT). Mapa Geológico do Estado de São Paulo: 1:500.000. São Paulo: IPT, vol. I, 1981 (Publicação IPT 1184).
JURCA, J. Classificações climáticas: variações temporoespaciais e suas aplicações nos livros didáticos e como subsídio ao zoneamento agroclimático. 2005. 100 f. Dissertação (Mestrado em Geografia) - Universidade Estadual Paulista, Faculdade de Ciências e Tecnologia, 2005. Disponível em: $<$ http://hdl.handle.net/11449/92837>.

KAISER, A., NEUGIRG, F., ROCK, G., MÜLLER, C., HAAS, F., RIES, J., SCHMIDT, J. Small-scale surface reconstruction and volume calculation of soil erosion in complex Moroccan gully morphology using structure from motion. Remote Sensing. Vol. 6, p. 7050-7080, 2014. DOI:10.3390/rs6087050.

NAKATA, A. A. M.; JULIAN, C. Aplicação de metodologias alternativas para recuperação de focos erosivos em áreas de nascentes no distrito de Amadeu Amaral, município de Marília/SP. 2018. 113f. Monografia (Graduação) Departamento de Planejamento, Urbanismo e Ambiente da Faculdade de Ciências e Tecnologia (UNESP) - Presidente Prudente, 2018.

POESEN, J. Challenges in gully erosion research. Landform Analysis, vol. 17, p. 5-9, 2011. Disponível em <https:// www.infona.pl/resource/bwmeta1.element.baztech-articleBUJ5-0051-0046> Acesso em: 30 jul. 2019.

ROSS, J. L. S.; MOROZ, I. C. Mapa geomorfológico do Estado de São Paulo. Rev. do Departamento de Geografia, São Paulo, n.10, 1996.

VERDONK, S. C. Gully volume estimates using UAV Photometry in the Salagou area. 13 abr. 2015. Dissertação (Master of Sciente) - University of Utrecht, 2015.

WADT, P. G. S; PEREIRA, J. E. S; GONÇALVES, R. C; ALVES, L. da S. Práticas de conservação do solo e recuperação de áreas degradadas. Rio Branco, AC: Embrapa Acre, 2003. 29 p. il. (Embrapa Acre. Documentos, 90).

WANG, R.; ZHANG, S.; PU, L.; YANG, J.; YANG, C.; CHEN, J.; GUAN, C.; WANG, Q.; CHEN, D.; FU, B.; SANG, X. Gully erosion mapping and monitoring at multiple scales based on multi-source remote sensing data of the Sancha river catchment, Northeast China. ISPRRS Int. Geo-Inf. vol. 5, n 11, 200, 2016. DOI:10.3390/ijgi5110200. 